\title{
CFD validation by measurement of specialized ventilation equipments on duct tract
}

\author{
Stanislav Sehnalek ${ }^{1, \star}$ \\ ${ }^{1}$ Tomas Bata University in Zlin, Faculty of Applied Informatics, Department of Automation and Control Engineering, Nad Stranemi \\ 4511, Zlin, Czech Republic
}

\begin{abstract}
This article describes measurement of HVAC distribution box on air duct track in Laboratory of Environmental Engineering (LEE). Firstly, the paper describes the LEE and then measurement apparatus with description of calculation methods. Then follows specification of sample with introduction to newly developed equipment for positioning of the anemometer. The evaluation of results of measurements with CFD comparison follows. The article is concluded with discussion over measured data with an outline for further research.
\end{abstract}

\section{Introduction}

Research of air mechanics is in concern of researchers for more than a century. Particulary the air flow parameters were investigated by Hagen, Reyleigh, Reynolds [1], followed up by Prandtl, Moody [2], Colebrook [3], Von Karman [4] and many others[5]. The prerequsite for a successful design technique is the knowledge of properties concerning HVAC components. Determination of parameters for specific HVAC devices are in scope of specialized laboratories. Laboratory of such capabilities is maintained by authors of this article at Tomas Bata University in Zlin, Faculty of Applied Informatics and is involved in this paper. Special interest in actual development is put on air divider for mounting in the ducts which is an important element within HVAC systems. In the authors' facility, the Laboratory of Environmental Engineering, it is possible to test the divider for all main parameters. In the presented paper, the focus is on measurement methods and comparison of results obtained by this standard with computational fluid dynamics (CFD). Mainly, the validation of CFD with measurement could lead to design better air dividers for HVAC purposes.

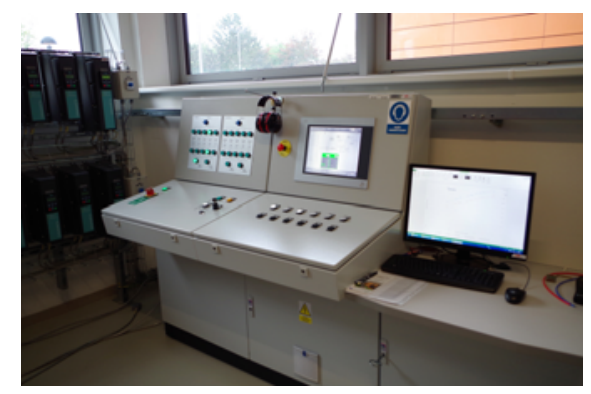

Fig. 1. Controlling board for duct tract

\footnotetext{
${ }^{\star}$ Corresponding author: sehnalek@ fai.utb.cz
}

Firstly, the article describes the methods of measurement with the test track. Above mentioned is linked with the description of the measurement method with characterization of used sample. A special device which helped with measurement process is also mentioned. Methods section is concluded with description of used CFD. Then the measured results are described, followed by discussion. The article is completed by used methods.

\section{Methods}

There is a possibility to measure volumetric flow of any equipment determined for installation inside a duct. For these measurements is used multiple-nozzle chamber (MNC) to resolve flow rate through the duct configuration. There is a wall taping mounted on MNC for measurement of pressure to resolve flow in accordance with ISO 5801 [6]. Calculations for air flow follows, in equations are made customization to match MNC which dispose authors at research facility.

$$
R e_{t}=\frac{0,95 d_{n} \sqrt{2 \rho \Delta p}}{17,1+0,048 \theta} 10^{6}
$$

Where $R e_{t}$ throat Reynolds number [-]

$d_{n} \quad$ diameter of nozzle $\quad[m]$

$\rho p \quad$ air density $\quad\left[\mathrm{kg} \mathrm{m}^{-3}\right]$

$\Delta p \quad$ pressure difference at nozzles $\quad[\mathrm{Pa}]$

$\theta \quad$ temperature of air $\quad\left[{ }^{\circ} \mathrm{C}\right]$

$$
\alpha=0,9986-\frac{7,00}{\sqrt{R e_{t}}}+\frac{134,6}{R e_{t}}
$$

Where $\alpha$ nozzle flow rate coefficient [-]

$$
q_{m}=\pi \sum_{i=1}^{m}\left(\alpha \frac{d_{n}}{4}\right) \sqrt{2 \rho \Delta p}
$$

Where $q_{m}$ mass flow $\left[\mathrm{kg} \mathrm{s}^{-1}\right]$ 


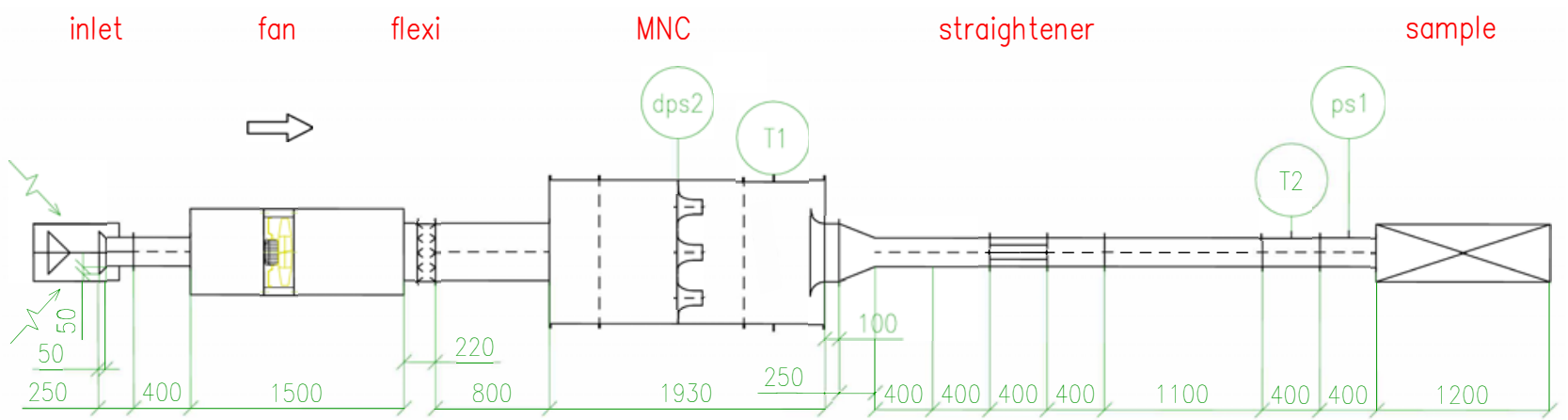

Fig. 2. Measurement track

\subsection{Fan track}

There are two available dimensions for the track. The diameters are $200 \mathrm{~mm}$ and $400 \mathrm{~mm}$. For each dimension there are available several types of duct which can be connected with each other. This function leads to many measurement variations. The track allows measurements of fan performance curve, loss coefficient, acoustic parameters, leakage and others. All components of the track are made in accordance with International standard ISO 5801. Controlling system of the track is handled by PLC with touch panel including visualization. All measured data are periodically saved to local FTP server in form of CSV file. The whole controlling board is depicted on Figure 1. On the left can be seen frequency converters for fans, next to these are buttons for switching circuit breaker, a touch panel with visualization for setting experiment and on the right is a computer unit.

Scheme of the measurement track is depicted in Figure 2. The whole length without the sample is almost $8 \mathrm{~m}$ long. The measurement track consists of inlet, ducts, fan, flexible joint, MNC, ducts, straightener, ducts and sample. Used ducts are of diameter $200 \mathrm{~mm}$.

\subsection{Measured sample}

As a measuring sample was used air divider for ventilation purposes. It consist of inlet with diameter of $160 \mathrm{~mm}$, inner rectangular part and ten outlets of diameter $62 \mathrm{~mm}$. To provide fully developed air, there have been added plastic pipes to each outlet. Big disadvantage of those is that it is delivered in twisted pack. That caused that it has tendency to twist. In order to prevent this from, happening a paper tube which is ordinary used for posters carrying was added. Length of outlet pipes was chosen to be $1000 \mathrm{~mm}$, which is around $16 D$, this ensured appropriate length to fully develop air profile. Final setup can be seen on Figure. 3 .

\subsection{Measuring equipment}

Measurement of air velocity at outlets was performed with vane apparatus. This anemometer can measure velocity up to $40 \mathrm{~ms}^{-1}$, with precision $\pm 3 \%$ from measured value. On the Figure 4 is positioning instrument with anemometer and measuring at one point.

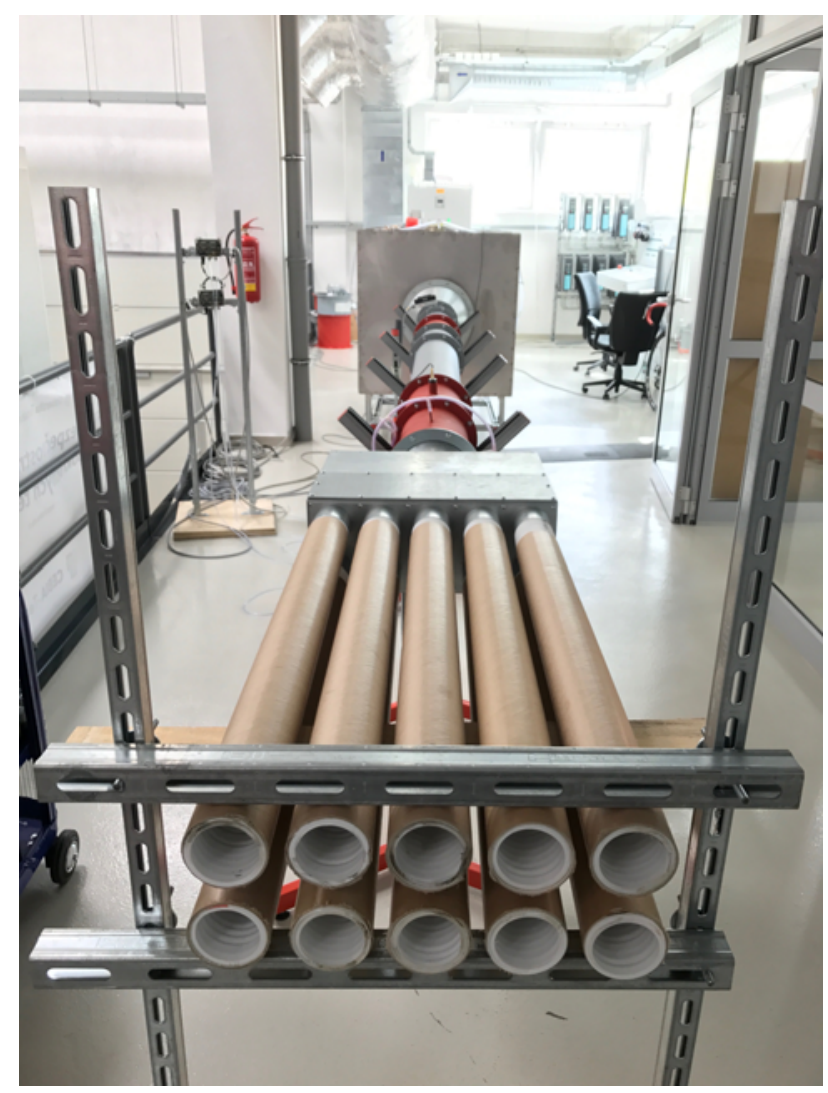

Fig. 3. Measured sample with measurement track

\subsection{Positioning instrument}

To ensure appropriate position of measurement in each point, there have been made positioning arrangement. Firstly were calculated positions of measuring points for considered diameter. This calculation was done based on log-linear assumption of velocity distribution in accordance with Winternitz and Fischl [7]. They hypothesized that the velocity distribution along a diameter can be represented by the equation 4 . In this assumption is duct divided to one central circular zone and number of annular zones, which all have equal area. Measuring points are at exact velocity mean zone. The reason to chose this method is based on research of Kinghorn and McHugh [8], who compared 14 traverse methods and log-linear had small- 


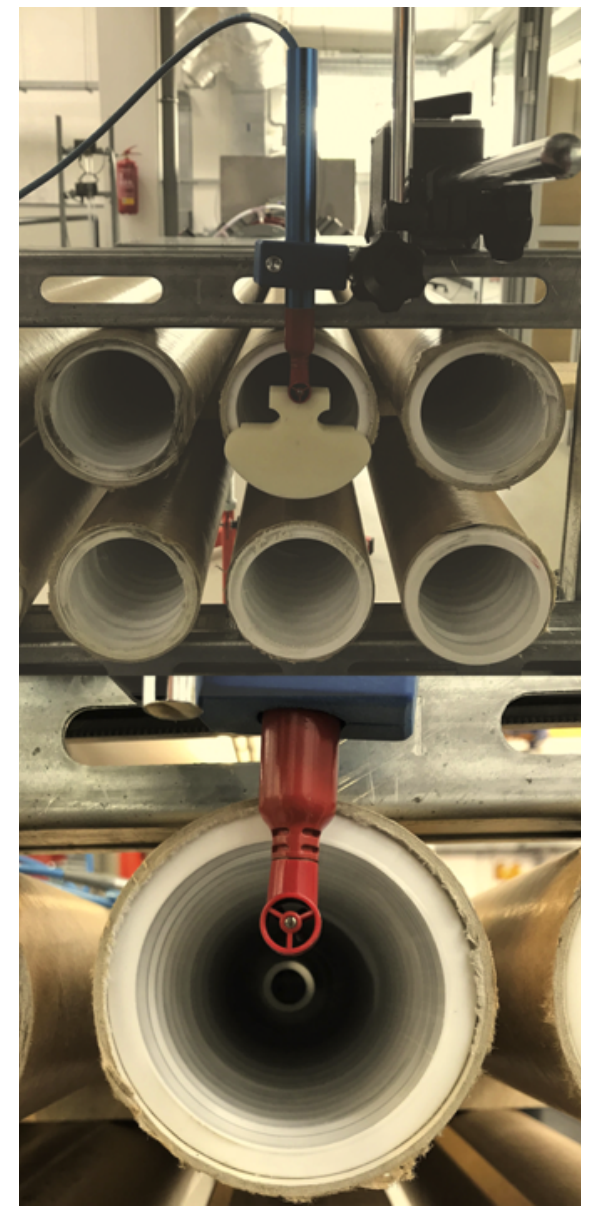

Fig. 4. Positioning of anemometer

est mean percentage deviation with orifice plate. Final traverse positions for measurement was $15 \mathrm{~mm}$ from the centre in 4 directions. Number of points and length was chose mandatory because of size of anemometer and because more points wouldn't had significant meaning.

$$
v_{y}=A+B \log \frac{y}{d}+C \frac{y}{d}
$$

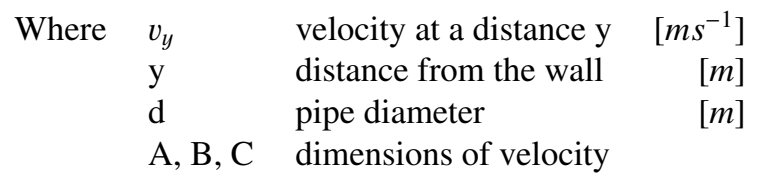

3D model was created after calculation of traverse position points in ANSYS SpaceClaim [9]. Due to complicated positions of sample outlets were modelled several configurations and then manufactured by $3 \mathrm{D}$ printer. Final instrument is shown on Figure. 5, above is computer model and beneath is a real model. To appropriately fix anemometer in position, a holder with magnetic base was used. This mounting have several degrees of freedom. This attribute is useful because during the measurement was mandatory to measure 4 positions at each outlet and simultaneously allow air to flow effortlessly. Fixation with anemometer was established also by 3D printed part.
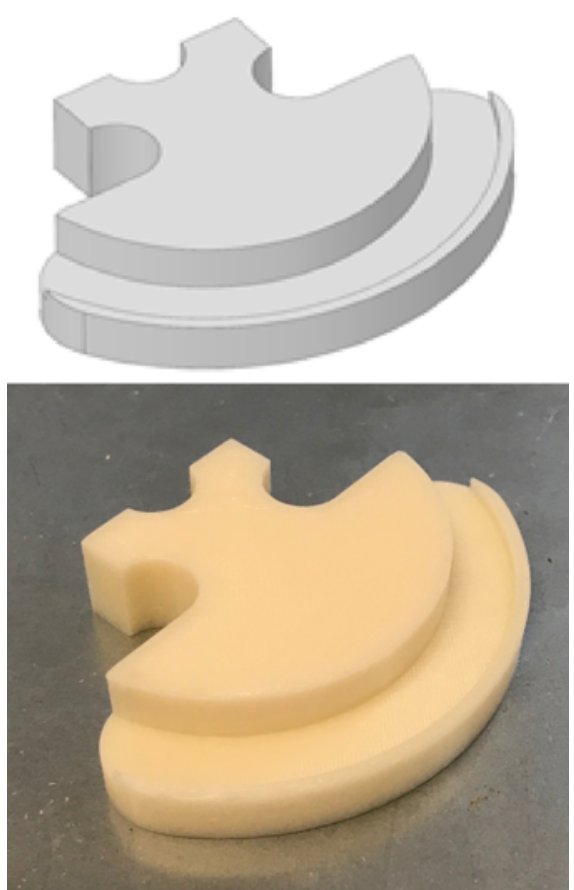

Fig. 5. Positioning instrument

\subsection{CFD set-up}

As computational fluid dynamic (CFD) software was used ANSYS Fluent in version 18 [10]. It was simulated only sample with boundary conditions of inlet pre-set to velocity measured by MNC to reduce computational costs. Outlet boundary conditions was set to gauge pressure of $0 P a$. Gravitational force was at $\mathrm{Z}$ direction and was set up to $-9,81 \mathrm{~ms}^{-2}$. For calculation were used two approaches of generating mesh. In the first one was maximal face size set to $0,002 m$ and edited inflation condition. Inflation boundary conditions is in high importance for fluid flow, because it generates boundary layers. First layer high $(\mathrm{Y}+)$ was calculated 5 based on [11] and was applied for all boundary regions same $\mathrm{Y}+$. Maximum number of layers was set to 10 with default growth rate of 1,2 . In the second approach were used same conditions and was calculated first layer high for each outlet based on measured velocity.

$$
\delta_{v}=122 d \frac{\ln (\operatorname{Re})}{\operatorname{Re} G(\ln R e)}
$$

$$
\begin{aligned}
& \text { Where } \delta_{v} \quad \text { sub-layer thickness } \quad[\mathrm{mm}] \\
& d \quad \text { pipe diameter } \quad[m] \\
& G(\ln R e) \quad \text { function which has } \\
& \text { a limit of } 1 \text { for } R e \rightarrow \infty \\
& \text { Re Reynolds number }
\end{aligned}
$$

\section{Results}

\subsection{Measurement on sample}

The data collection was started after fixation of anemometer in appropriate point and outlet. For each point was measured velocity every second for half a minute. This 

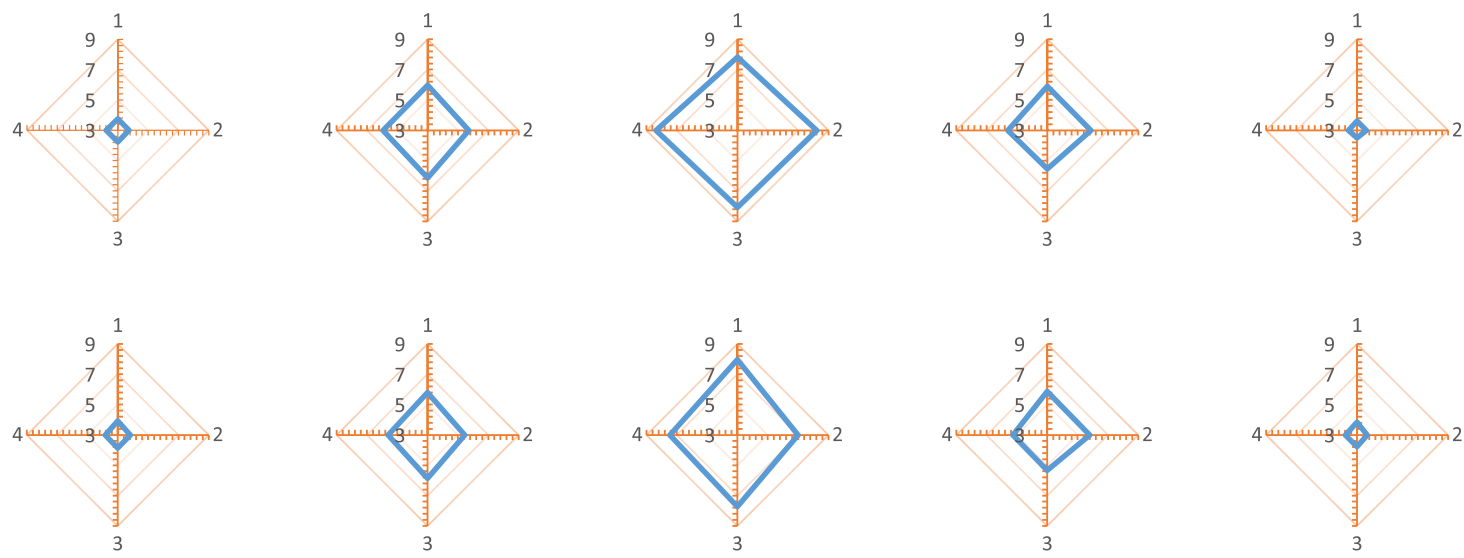

Fig. 6. Distribution of velocity at each outlet $\left[\mathrm{ms}^{-1}\right]$

gives more then 120 values for calculating mean velocity at each outlet which is summarized in table 1 . Also is calculated expanded uncertainty $\sigma$ with coverage factor $k=2$ in accordance to international standard JCGM 100:2008 [12]. The volume flow $\dot{V}$ was calculated from velocity. Total volume flow by anemometer was $(0,162 \pm 0,019)\left[\mathrm{m}^{3} \mathrm{~s}^{-1}\right]$. Measurement on MNC was performed by pressure transmitter with standard uncertainty of type $\mathrm{A} \pm 0,577 \mathrm{~Pa}$ and type $\mathrm{B}$ from calibration of $\pm 0,3 \%$ and of reading $\pm 0,03 P a$. Expanded uncertainty is then $\pm 1,249 P a$ with coverage factor of 2 . When is calculated with equations 1,2 and 3 the volumetric flow is $(0,151 \pm 0,036)\left[m^{3} s^{-1}\right]$. This difference is around $6,8 \%$ and is mainly due to the principle of measurement by anemometer but it is in range of uncertainty. The reason is that during the measurement process anemometer makes obstacle to the flow which then makes quicker streamlines. Next reason is due to swirling stress caused by aerodynamic forces on the rotor blading [13]. This fact and uncertainty of both methods make above mentioned difference non essential for purposes of this article. Distribution of velocities is depicted in Figure. 6, where upper left is outlet position one, next to it is second and so on. From above mentioned is apparent that air velocity distribution is not symmetrical at each outlet which leads to different air distribution in HVAC system. So is difficult to assemble such distributing box and appropriately balance each outline.

\subsection{CFD on sample}

In previous part was measured air volume flow between 0,151 to $0,162\left[\mathrm{~m}^{3} \mathrm{~s}^{-1}\right]$ from which was taken in account measurement of MNC and so inlet air velocity for $D N 200$ is around $4,8 \mathrm{~ms}^{-1}$ thus Reynolds number was calculated 64000 . Placed on before determined parameters was computed sub-layer high $(Y+)$ at inlet as $3,12510^{-3} \mathrm{~m}$. For outlets values was calculated at each outlet based on measured velocities and is summarized in table 1 . Difference in generated mesh is summarized in table 2.
Table 1: Measured air velocity distribution at outlets

\begin{tabular}{ccccc} 
position & $v\left[\mathrm{~ms}^{-1}\right]$ & $\sigma\left[\mathrm{ms}^{-1}\right]$ & $\dot{V}\left[\mathrm{~m}^{3} \mathrm{~s}^{-1}\right]$ & $Y+[\mathrm{mm}]$ \\
\hline 1 & 3,759 & 0,080 & 0,011 & 3,514 \\
2 & 5,936 & 0,315 & 0,018 & 2,329 \\
3 & 8,118 & 0,419 & 0,025 & 1,755 \\
4 & 5,729 & 0,330 & 0,017 & 2,405 \\
5 & 3,574 & 0,129 & 0,011 & 3,677 \\
6 & 3,858 & 0,099 & 0,012 & 3,432 \\
7 & 5,675 & 0,391 & 0,017 & 2,426 \\
8 & 7,538 & 0,726 & 0,023 & 1,877 \\
9 & 5,570 & 0,555 & 0,017 & 2,467 \\
10 & 3,763 & 0,144 & 0,011 & 3,510
\end{tabular}

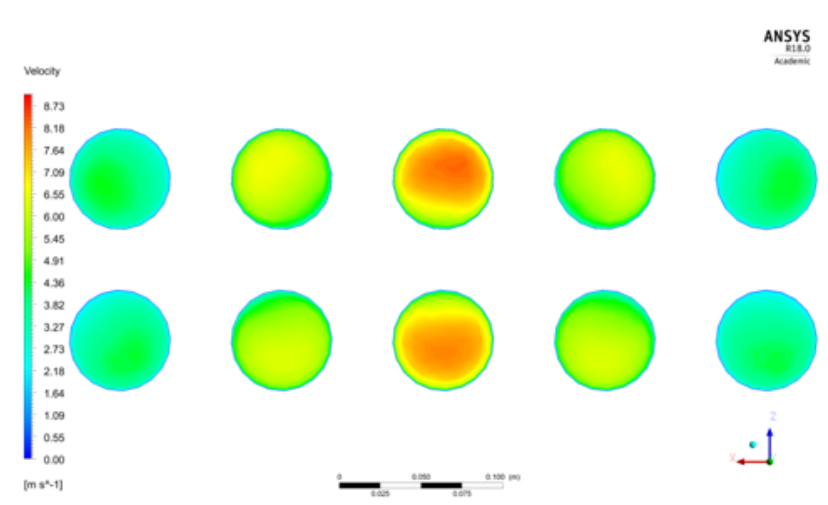

Fig. 7. Countours of velocity at outlets

From Figure. 8 and 9 is apparent non symmetrical air distribution. This fact is in correlation with measured data as shows Figure. 7.

\section{Conclusion}

From above mentioned is apparent that air velocity distribution is not symmetrical at each outlet which leads to different air distribution in HVAC system. It is difficult to assemble such distributing box and appropriately balance 
Table 2: Comparison of generated meshes

\begin{tabular}{ccc} 
& one $\mathrm{Y}+$ mesh & each $\mathrm{Y}+$ mesh \\
\hline nodes & 493384 & 559048 \\
elements & 1654298 & 1263217
\end{tabular}

Table 3: Volumetric flow comparison $\left[\mathrm{m}^{3} \mathrm{~s}^{-1}\right]$

\begin{tabular}{cccc} 
Position & measurement & simulation & difference \\
\hline 1 & 0,0113 & 0,0106 & 0,0008 \\
2 & 0,0179 & 0,0160 & 0,0020 \\
3 & 0,0245 & 0,0207 & 0,0038 \\
4 & 0,0173 & 0,0163 & 0,0010 \\
5 & 0,0108 & 0,0108 & 0,0000 \\
6 & 0,0116 & 0,0110 & 0,0007 \\
7 & 0,0171 & 0,0165 & 0,0006 \\
8 & 0,0228 & 0,0211 & 0,0017 \\
9 & 0,0168 & 0,0168 & 0,0000 \\
10 & 0,0114 & 0,0111 & 0,0003
\end{tabular}

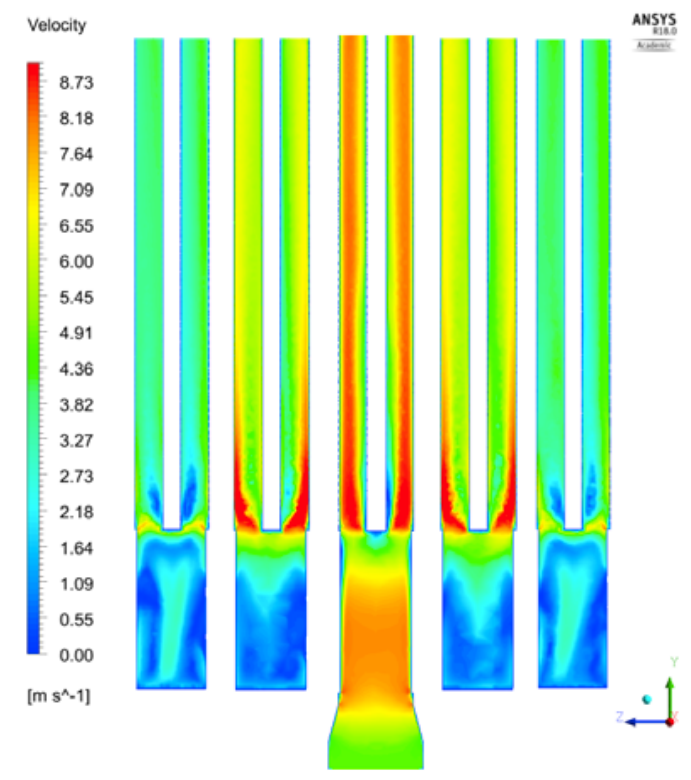

Fig. 8. Countours of velocity from simulation (side views)

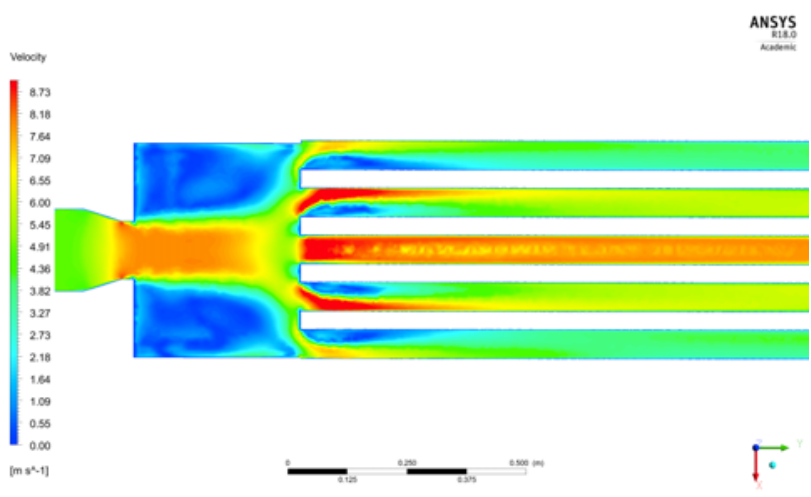

Fig. 9. Countours of velocity from simulation (top view)

each branch. The purpose of the paper was to evaluate and outline CFD simulation for HVAC equipment. Further research will focus on align air velocity equally at all outlets by CFD with later validation by measurement of final solution.

This work was supported by the Ministry of Education, Youth and Sports of the Czech Republic within the National Sustainability Programme project No. LO1303 (MSMT-7778/2014) and also by the Internal Grant Agency of Tomas Bata University in Zlin under the project No. IGA/CebiaTech/2017/002.

\section{References}

1. O. Reynolds, Proceedings of the Royal Society of London 35, 24 (1883)

2. L.F. Moody, Transaction of the A.S.M.E. 66, 14 (1944)

3. C.F. Colebrook, Journal of the Insitution of Civil Engineers 11, 29 (1939)

4. T. Von Kármán, L. Edson, The Wind and Beyond: Theodore Von Kármán, Pioneer in Aviation and Pathfinder in Space (Little, Brown, 1967)

5. P.A. Davidson, Y. Kaneda, K. Moffatt, K.R. Sreenivasan, A voyage through turbulence (Cambridge University Press, 2011)

6. CSN EN ISO 5801:2009, Standard, Czech office for standards metrology and testing, Prague, CZ (2009)

7. F.A.L. WINTERNITZ, C.F. FISCHL, Water Power 9 , 225 (1957)

8. Kinghorn, F. C., McHugh, A., La Houille Blanche pp. 49-58 (1977)

9. Ansys fluent user's guide (2017)

10. Spaceclaim 2015 user's guide (2015)

11. H. Schlichting, K. Gersten, Boundary-Layer Theory (Springer Berlin Heidelberg, 2017), ISBN 978-3-66252917-1

12. J.C. for Guides in Metrology, Tech. rep., JCGM (2008)

13. W. Merzkirch, Fluid Mechanics of Flow Metering (Springer, 2005), ISBN 9783540222422 